\title{
Immune escape and immunotherapy of acute myeloid leukemia
}

\author{
Luca Vago ${ }^{1,2}$ and Ivana Gojo ${ }^{3}$

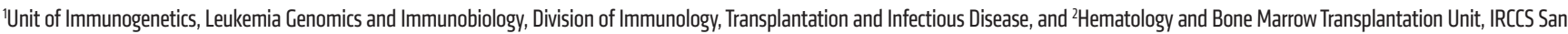 \\ Raffaele Scientific Institute, Milano, Italy. 3Division of Hematologic Malignancies, Department of Oncology, Sidney Kimmel Comprehensive Cancer Center at Johns Hopkins, Baltimore, Maryland, USA.
}

\begin{abstract}
In spite of the recent approval of new promising targeted therapies, the clinical outcome of patients with acute myeloid leukemia (AML) remains suboptimal, prompting the search for additional and synergistic therapeutic rationales. It is increasingly evident that the bone marrow immune environment of AML patients is profoundly altered, contributing to the severity of the disease but also providing several windows of opportunity to prompt or rewire a proficient antitumor immune surveillance. In this Review, we present current evidence on immune defects in AML, discuss the challenges with selective targeting of AML cells, and summarize the clinical results and immunologic insights from studies that are testing the latest immunotherapy approaches to specifically target AML cells (antibodies, cellular therapies) or more broadly reactivate antileukemia immunity (vaccines, checkpoint blockade). Given the complex interactions between AML cells and the many components of their environment, it is reasonable to surmise that the future of immunotherapy in AML lies in the rational combination of complementary immunotherapeutic strategies with chemotherapeutics or other oncogenic pathway inhibitors. Identifying reliable biomarkers of response to improve patient selection and avoid toxicities will be critical in this process.
\end{abstract}

\section{Introduction}

Acute myeloid leukemia (AML) is a genetically, epigenetically, and clinically heterogeneous disease characterized by accumulation and expansion of immature myeloid cells in the bone marrow $(\mathrm{BM})$ and peripheral blood $(\mathrm{PB})$, with consequent failure of normal hematopoiesis (1). Advances in genomic and epigenomic characterization of AML have fostered better understanding of leukemogenesis, paving the way for development and approval of several novel targeted therapies. Still, the mainstay of treatment is chemotherapy, which has remained mostly unchanged over the past four decades. Fewer than one-third of adult AML patients enjoy durable remission, indicating a need for different therapeutic approaches. Immunotherapy carries a promise to eradicate chemoresistant clone(s) and provide long-term disease control.

Historically, AML has been considered an immunoresponsive malignancy and continues to represent the most common indication for which patients receive allogeneic hematopoietic stem cell transplantation (alloHSCT) $(2,3)$. However, modest association of graft-versus-host disease with relapse reduction in AML (4), and alloHSCT's inability to prevent relapse in most patients who undergo transplantation with active disease (5), underscore the limited effectiveness of alloreactive $\mathrm{T}$ cells and a need for more potent and specific targeting of AML.

In this Review we discuss the hurdles of finding suitable targets for AML immunotherapy, summarize the immune features of the leukemia microenvironment, review results obtained in clini-

Conflict of interest: IG received research funding from Merck, Amgen, and Amphivena. Copyright: $\odot 2020$, American Society for Clinical Investigation.

Reference information: J Clin Invest. 2020;130(4):1552-1564.

https://doi.org/10.1172/JCl129204. cal trials using novel strategies such as bispecific antibodies, cell therapies, and checkpoint blockade, and ultimately discuss how this information might translate into future developments.

\section{Selecting antigen targets in $\mathrm{AML}$}

Finding an antigen target that is critical for AML biology and selectively expressed on malignant cells remains a challenge. Besides AML's heterogeneity, the complexity of its clonal composition and propensity to change with disease progression further complicate this quest.

Antigen targets in AML can generally be divided into lineage-restricted antigens (LRAs), leukemia-associated antigens (LAAs; wild-type proteins overexpressed in leukemia versus normal cells), and leukemia-specific antigens (LSAs; neoantigens originated by mutations in protein-coding genes). The LRAs (Table 1), which are expressed on the surface of leukemia cells, are suitable targets for approaches based on antibodies or chimeric antigen receptor (CAR) T cells, but are often shared with normal hematopoietic or even non-hematopoietic tissues, and their utility as immunotherapeutic targets is mostly countered by on-target toxicity. On the other hand, despite their higher leukemia cell specificity, LAAs (e.g., WT1 [ref. 6]) and LSAs (e.g., mutated NPM1 [ref. 7]) are often expressed intracellularly, and their potential as immunotherapeutic targets depends on their ability to be processed and presented to T cells within the HLA complex (8). CD33 and CD123 are the LRAs that have been most studied in AML, but myelosuppression has been of concern due to their expression on normal hematopoietic tissues (9-11). In fact, integrated transcriptomic and proteomic analysis of AML surfaceome failed to identify a single surface antigen that meets the favorable characteristics of CD19 in acute lymphoid leukemia (ALL) (12), 
Table 1. Select lineage-restricted surface AML antigen targets

\begin{tabular}{|c|c|c|c|c|}
\hline Antigen & Description & AML blast expression & LSC expression & Normal tissue expression \\
\hline CD33 (Siglec-3) & Transmembrane receptor & $90 \%$ & Yes & $\begin{array}{l}\text { HSCs; myeloid progenitors, monocytes, mast cells, } \\
\text { Kupffer cells, microglial cells in the brain }\end{array}$ \\
\hline CD123 (IL-3R $\alpha)$ & IL-3 receptor- $\alpha$ & $50 \%-100 \%$ & Yes & $\begin{array}{l}\text { HSCs (little or no); myeloid progenitors, monocytes, basophils, } \\
\text { dendritic cells, epithelial cells (respiratory, gastrointestinal) }\end{array}$ \\
\hline CLL1 (CLEC2A) & Transmembrane receptor & $77 \%-100 \%$ & Yes & Monocytes, granulocytes, tissue-resident lung macrophages \\
\hline CD44v6 & $\begin{array}{l}\text { Transmembrane receptor/splice } \\
\text { variant }\end{array}$ & $64 \%$ & Yes & $\begin{array}{l}\text { Monocytes, keratinocytes; different epithelial tissues } \\
\text { (respiratory, gastrointestinal, genitourinary) }\end{array}$ \\
\hline Lewis Y (CD174) & Blood group carbohydrate antigen & $50 \%$ & Likely & HSCs; intestinal epithelial cells \\
\hline FLT3 (CD135) & Type III receptor tyrosine kinase & $70 \%-100 \%$ & Yes & HSCs; myeloid progenitors, neurons \\
\hline CD7 & $\begin{array}{l}\text { Transmembrane protein; member of } \\
\text { the immunoglobulin superfamily }\end{array}$ & $30 \%$ & Possibly & T cells \\
\hline FOLR2 (folate receptor- $\beta$ ) & Folate-binding protein receptor & $70 \%$ & Possibly & Myeloid cells, macrophages \\
\hline
\end{tabular}

Others include IL1RAP (IL-1 receptor accessory protein), CD64 (Fc receptor that binds IgG), CD13 (type II membrane glycoprotein-aminopeptidase N), CD38 (cyclic ADP ribose hydroxylase), CD45 (tyrosine phosphatase), CD15 (adhesion molecule, carbohydrate antigen), and NKC2D/NKC2DL (C-type lectin-like transmembrane receptor protein). LSC, leukemia stem cell.

but identified several target pairings or combinations that could potentially enhance selective targeting of AML cells (13).

Several LAAs are considered leukemia-restricted given their very low expression (hTERT, survivin) or tissue-specific expression (oncofetal antigen-immature laminin receptor antigen [OFA-ILRP] and the cancer/testis antigens PRAME and MAGE) in other compartments $(8,14,15)$. Among different LAAs, WT1 protein has gathered substantial attention $(6,16)$ : clinical trials with $\mathrm{T}$ cells genetically redirected against WT1 generated promising results without significant off-target tissue toxicity (17), and WT1-specific $\mathrm{CD}^{+}$responses were detected in vaccine trials in AML patients $(18,19)$. Other LAAs such as PR1, hTERT, and PRAME were found to elicit $\mathrm{CD}^{+} \mathrm{T}$ cell or humoral responses in vivo in leukemia patients after vaccination (20-26), while immune responses against a broader range of LAAs were detected in the post-transplant setting (reviewed in ref. 27).

AML is characterized by one of the lowest mutational burdens among diverse malignancies (28). Nonetheless, while the frequency of immunogenic mutations creating neoantigens (i.e., LSAs) is expected to be low, mutational quality rather than quantity may be relevant in eliciting antileukemia responses. Several common translocations (AML1-ETO, DEC-CAN, PML-RAR $\alpha$, BCR-ABL) and gain-of-function mutations (FLT3-ITD, NPM1, IDH1 ${ }^{\mathrm{R} 132 \mathrm{H}}$ ) produce $\mathrm{AML}$-specific immunogenic proteins that drive the malignant phenotype and thus represent ideal antigen targets. In addition, unlike LAAs, neoantigens are not part of the "self" antigen repertoire, and thus are unlikely to be subject to central tolerance (29). As a consequence, ex vivo isolation or in vivo expansion of high-affinity $\mathrm{T}$ cells against LSAs from AML patients or healthy individuals appears more likely than use of historical LAAs, and is currently an object of intense investigation $(30,31)$. In particular, mutated cytoplasmic protein NPM1 (found in $30 \%$ of AML patients) can induce $\mathrm{CD} 4^{+}$and $\mathrm{CD} 8^{+} \mathrm{T}$ cell responses $(7,32)$, and the $\mathrm{IDH} 1^{\mathrm{R} 132 \mathrm{H}}$ mutation that is common to both AML and gliomas has been shown to generate an HLADR-restricted neoantigen recognized by $\mathrm{CD} 4^{+} \mathrm{T}$ cells (33). Finally, several TP53 "hotspot" mutations have been shown to give rise to immunogenic neoepitopes (34), and studies have linked TP53 to the immunosuppressive BM environment in AML (35) and to response to checkpoint blockade in solid tumors $(36,37)$.

Several additional mechanisms may provide antigen targets in AML. Notably, AML is enriched for spliceosome mutations, and recent studies have identified aberrant splice variants for $29 \%$ of expressed genes genome-wide in AML compared with normal donor $\mathrm{CD} 34^{+}$cells. The most commonly mis-spliced genes $(>70 \%$ of AML patients) were NOTCH2 and FLT3, encoding myeloid cell surface proteins (38). CD44v6, a splice variant of the ubiquitously expressed hyaluronate receptor CD44, is expressed on AML blasts but not on normal HSCs, rendering it an attractive target for CAR $\mathrm{T}$ cell therapy (39). Dysregulated posttranslational modification can also provide a source of antigens that can stimulate immune responses. A recent study identified 61 phosphopeptides specifically presented on the surface of hematologic tumors but not normal tissues and documented robust $\mathrm{CD} 8^{+} \mathrm{T}$ cell responses against many of these phosphopeptides in healthy individuals (40).

Lastly, in addition to HLA class I and II proteins presenting peptide antigens, CD1-lineage proteins present lipids and glycolipids to T cells. In particular, C16 methyl-lysophosphatidic acidspecific (C16 mLPA-specific) CD1c-restricted T cells could kill CD1c-expressing primary AML blasts (41).

In the design of immunotherapeutic strategies it should, however, be considered that each of these antigens, when targeted individually, faces the issue of genetic loss, mutation, or downregulation and, in the case of peptide or lipid antigens, loss of the restriction element (42). The documented success of alloHSCT in controlling or eradicating AML might conversely relate to the fact that a wide repertoire of $\mathrm{T}$ cells is transferred from the donor to the patient $(27,43)$, recognizing not only LAAs and LSAs, but also 


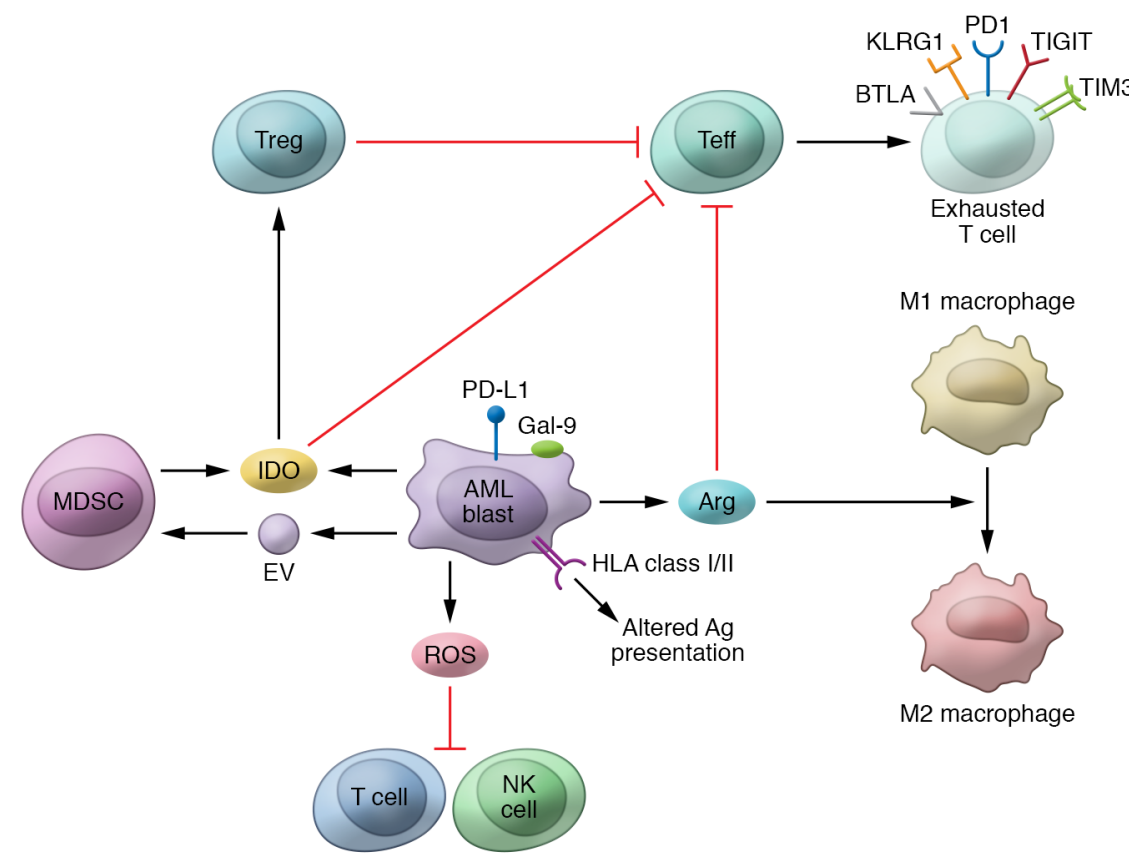

Figure 1. The pathologic immune microenvironment of acute myeloid leukemia. The illustration summarizes known leukemia-intrinsic and -extrinsic immune evasion mechanisms. As described in the main text, AML blasts can reduce their expression of antigen presentation molecules, overexpress inhibitory T cell ligands (including PD-L1, Gal-9, and others), and release in the bone marrow niche reactive oxygen species (ROS), indoleamine 2,3-dioxygenase (IDO), arginase (Arg), and extracellular vesicles (EVs). This, in turn, can inhibit the cytotoxic function of $T$ and NK cells, drive effector T cell (Teff) exhaustion and apoptosis, induce regulatory T cells (Tregs) and myeloid-derived suppressor cells (MDSCs), and promote the switch of macrophages from M1 to suppressive M2 phenotype.

minor histocompatibility antigens (the number of which exceeds by several orders of magnitude those of tumor antigens [refs. 44, 45]) and incompatible HLA molecules (each recognized by multiple T cell clonotypes [ref. 46]).

\section{Immune state in $\mathrm{AML}$ and immune evasion mechanisms}

Multiple mechanisms are implicated in AML's immune evasion, as depicted in Figure $1(47,48)$. Each mechanism's exact contributions to leukemia immune tolerance, how mechanisms operate in $\mathrm{PB}$ versus BM (primary tumor site) versus extramedullary tissues, and how they are affected by AML treatment or influenced by AML genetics require further understanding.

Altered antigen presentation. Leukemia blasts exhibit impressive immunoediting capabilities under the selective immune pressure that occurs after alloHSCT (49), as evidenced by loss of mismatched HLAs in haploidentical transplants (50-52) or epigenetic downregulation of HLA class II molecules in different donor transplant settings $(53,54)$. Deletional $\mathrm{T}$ cell tolerance and $\mathrm{CD}^{+} \mathrm{T}$ cell tolerance induction due to leukemia antigen presentation by immature antigen-presenting cells or splenic CD $8 \alpha^{+}$dendritic cells (DCs), respectively, have both been reported in mouse models of AML $(55,56)$. Recently, loss of plasmacytoid DC differentiation was linked to persistence of measurable residual disease after AML treatment and inferior survival outcomes (57).

$T$ and NK cells. The presence of T cells at the tumor site is the prerequisite for immune recognition and elimination of AML cells, and for any therapy leveraging on this axis. Relative to healthy controls (HCs), AML patients have a comparable number of $\mathrm{T}$ cells in $\mathrm{BM}$ and even higher levels of total and $\mathrm{CD} 8^{+} \mathrm{PB}$ T cells $(58,59)$. Higher percentages of lymphocytes and T lymphocytes in BM correlated with improved response and survival (60), and robust lymphocyte recovery following chemotherapy was associated with reduced relapse risk (61). Recently, higher percentages of $\mathrm{CD}^{+}$and $\mathrm{CD}^{+} \mathrm{T}$ cells in $\mathrm{BM}$ were found to predict response to the checkpoint inhibitor (CPI) nivolumab in combination with hypomethylating agent (HMA) (62).

Regarding $\mathrm{T}$ cell function, a study in a mouse model of AML showed that the frequencies of $\mathrm{CD}^{+} \mathrm{T}$ cells expressing the checkpoint inhibitory receptor (CIR) PD-1 and Tregs increase at the tumor site with disease progression, and highlighted the therapeutic potential of PD-L1/PD-1 blockade and Treg depletion (63). Similarly, increased frequency of functionally exhausted $\mathrm{CD} 8^{+} \mathrm{T}$ cells coexpressing the CIRs PD- 1 and TIM3 coincided with disease progression in a mouse model of AML; these cells' cytotoxic function was reinvigorated by combined checkpoint inhibition (64). Phenotypic and gene expression profiling of $\mathrm{PB} \mathrm{CD} 8^{+}$and $\mathrm{CD}^{+} \mathrm{T}$ cells in AML patients at diagnosis identified an aberrant activation profile and alterations in genes important for immunologic synapse formation (58). Subsequently, it was suggested that T cells in AML are functionally intact in terms of cytokine production and proliferation, with the exception of reduced IFN- $\gamma$ production by $\mathrm{CD}^{+}$ $\mathrm{T}$ cells, and that PD-1 upregulation reflects changes in $\mathrm{T}$ cell differentiation toward effector memory cells (65). Several groups, including ours, reported that the frequency of $\mathrm{T}$ cells coexpressing CIRs in AML patients is higher than that of $\mathrm{T}$ cells coexpressing CIRs in healthy controls, and that the frequency of T cells coexpressing CIRs (PD-1 and TIM3; PD-1 and LAG3) increases with disease progression $(47,59)$. Several smaller studies found that CIR-expressing $\mathrm{CD} 8^{+} \mathrm{T}$ cells are functionally impaired and predictive of AML relapse (66-70). While general cytokine expression by $\mathrm{CD}^{+} \mathrm{T}$ cells in AML patients may not substantially differ from that in healthy controls, senescent and exhausted $\mathrm{T}$ cells with markedly different cytokine expression profile have been identified. In-depth profiling of $\mathrm{CD} 8^{+} \mathrm{T}$ cells, however, suggested reversibility of transcriptional T cell signatures in responders to induction chemotherapy (47). A recent 
study also suggests that $\mathrm{BM} C D 8^{+} \mathrm{T}$ cells promote expansion of leukemia stem cells (LSCs) in favorable-risk AML, whereas LSC expansion in adverse-risk AML is cell-intrinsic and independent of $\mathrm{CD}^{+} \mathrm{T}$ cells (71). Lastly, the frequency of PD-L1 ${ }^{+}$ AML cells varied across different studies from $18 \%$ to more than $50 \%$. PD-L1 expression appears to increase at the time of relapse, is more frequently noted on acute monocytic leukemia, and is associated with poor prognosis $(59,72-75)$. Additionally, upregulation of PD-L1 and other cosignaling ligands on AML blasts with corresponding changes in T cells was identified as an immune escape mechanism in post-alloHSCT relapse $(54$, 76). IFN- $\gamma$ exposure strongly increases PD-L1 expression on leukemia blasts (77-79), and rapid PD-L1 upregulation by primary AML blasts as an adaptive immune response-driven resistance mechanism was observed upon treatment with immunotherapeutics that activate T cells $(42,80-82)$.

Leukemic blasts play a critical role in modulating $\mathrm{T}$ cell response, and $\mathrm{T}$ cell exposure to AML blasts in vitro leads to T cell apoptosis, inhibition of proliferation, and downregulation of costimulatory molecule expression. Monocytic leukemia cells produce ROS, which kills $\mathrm{T}$ cells and NK cells by triggering poly(ADP-ribose) polymerase-1dependent (PARP-1-dependent) apoptosis (83). NK cytotoxicity and effector function were also reduced upon exposure to AML blasts in vitro. Functionally impaired NK cells with reduced expression of activating receptors and upregulation of the inhibitory receptor NKG2A are already present in AML patients at diagnosis. Like those in $\mathrm{T}$ cells, the phenotypic and functional changes in NK cells were partially reversible upon achievement of remission but persisted in nonresponders to therapy $(84,85)$. The aberrant leukemia-specific fusion proteins PML-RAR $\alpha$ and AML1-ETO were shown to specifically downregulate CD48 (the ligand of the NK cell receptor 2B4, or CD244) on AML cells, resulting in impaired NK cytolytic activity (86).

Immunosuppressive microenvironment. Studies in mice and humans also implicate Tregs as a major contributor to defective immune responses in AML (87). Tregs are increased in PB and $\mathrm{BM}$ of AML patients, where they exhibit more potent immunosuppressive effects on effector $\mathrm{T}$ cells (Teffs) than their normal counterparts, and are minimally affected by chemotherapy ( 59 , 88). Moreover, increased Treg levels appear to be associated with worse outcomes in AML $(88,89)$.

Myeloid-derived suppressor cells (MDSCs) also appear to be increased in AML patients, inducing T cell tolerance through multiple mechanisms, including VISTA, PD-L1, indoleamine 2,3-dioxygenase (IDO), arginase, excess ROS, peroxynitrate, and multiple cytokines (TGF- $\beta$ and IL-10) (90-94). AML cells may induce MDSC expansion by releasing extracellular vesicles (EVs) containing the oncoprotein MUC1, which, in turn, increases c-myc expression in EVs, leading to MDSC proliferation (95). Positive correlation between the number of Tregs and that of MDSCs was found in high- but not in low-risk myelodysplasia (MDS), indicating Tregs' and MDSCs' potential role in disease progression (96).

Several enzymes expressed by AML blasts may contribute to the suppressive microenvironment. AML blast expression of IDO, an enzyme that catalyzes the rate-limiting step of tryptophan degradation along the kynurenine pathway, is associated with shortened relapse-free survival and overall survival (OS) (97-99). Depletion of tryptophan and accumulation of its metabolites result in inhibition of Teff proliferation, increased $\mathrm{T}$ cell apoptosis, and Treg induction (100). Arginase II, produced by AML blasts, is increased in patients with AML and suppresses $\mathrm{T}$ cell proliferation, inhibits myeloid-monocytic differentiation, and promotes monocyte polarization into a suppressive M2-like phenotype (101). In animal models of monocytic AML, arginase I was also associated with leukemia aggressiveness, driving tissue infiltration and T cell suppression through a signaling pathway involving the LILRB4 receptor (102).

\section{Immunologic effects of common antileukemia therapies}

Although they were primarily developed to be cytotoxic or to inhibit oncogenic pathways, it is increasingly recognized that most of the AML therapeutics have potent effects on the immune system and on leukemia immunogenicity, which may be further enhanced in specific settings, such as after alloHSCT.

For instance, exposing leukemia cells to cytarabine, even at low doses, can increase expression of HLA class II and the costimulatory molecule CD80, and downregulate PD-L1 expression (103). Anthracyclines, on the other hand, can induce immunogenic cell death, leading to cell surface translocation of calreticulin and extracellular release of ATP and HMGB1 and ultimately promoting DC-based cross-priming of antileukemia T cells (104). Notably, pretreatment calreticulin exposure on AML blasts significantly correlated with superior OS following treatment (105). However, anthracyclines can also elicit immunosuppressive pathways, such as induction of IDO1 in DCs (106).

In AML, and other myeloid malignancies, founder mutations occur frequently in genes that regulate DNA methylation (e.g., DNMT3A, TET2, and IDH1/2) or chromatin remodeling (e.g., ASXL1, EZH2, and KMT2A) (107). A number of drugs modulating the activities of these epigenetic regulators, including HMAs, have been approved for MDS and AML.

Interestingly, a sizable number of immune-related genes increase their expression upon HMA exposure, and second-generation HMA guadecitabine might have even more potent immune-related effects compared with azacitidine and decitabine (108). Genes known to be upregulated in AML cells upon exposure to HMAs include those encoding HLA class I and II molecules, their regulators, and many cancer/testis antigens or LAAs, including MAGE, PRAME, and WT1 (109). More recently, studies performed in epithelial malignancies demonstrated that HMAs can promote reactivation of dormant human endogenous retroviruses, which, upon transcription, elicit innate immune sensing and induction of adaptive responses $(110,111)$. In addition, azacitidine was shown to improve T cell repertoire in MDS (112), and its efficacy in combination with donor lymphocyte infusion in the post-alloHSCT setting supports azacitidine's ability to induce tumor-specific responses (113-115).

On the other hand, DNA methylation tightly regulates expression of several immune checkpoints, and exposing leukemia cells to HMAs was shown to elicit PD-L1 upregulation (116). For these reasons, HMAs have been combined with immune CPIs in clinical studies in AML, discussed in more detail below. However, HMAs were also shown to reduce methylation of the FOXP3 promoter, promoting Treg expansion (117). 
Finally, drugs that selectively block an oncogenic pathway can have considerable immunotherapeutic activity, as evidenced by a recent study on FLT3-mutated AML relapsed after alloHSCT and treated with the multi-tyrosine kinase inhibitor (TKI) sorafenib. In animal models and patient samples, FLT3 inhibition prompted leukemic blasts to release IL-15, which in turn potentiated responses mediated by early-differentiated $\mathrm{T}$ and NK cells (118). Other TKIs, including BCR-ABL inhibitors, can exert immune-related effects by inducing mature NK cells and leukemia antigen-specific $\mathrm{T}$ cells and decreasing the frequency of Tregs and PD-1+ $\mathrm{T}$ cells (119). Moreover, studies in epithelial malignancies demonstrated that selective inhibition of genes commonly mutated or deregulated in AML, such as RAS and MYC, can indirectly boost antitumor responses $(120,121)$.

\section{Antibody therapy in AML}

The anti-AML activity of antibodies relies on their ability to (a) recruit immune effectors via their $\mathrm{Fc}$ domain, causing NK cell antibody-dependent cellular cytotoxicity (ADCC), antibodydependent cell phagocytosis, or complement-dependent cytotoxicity; (b) deliver toxic payload after receptor-mediated internalization of antibody-drug conjugates (ADCs) and radionuclide conjugates; or (c) enhance T or NK cell antileukemia efficacy by engaging these cells with the target leukemia cells using bispecific or polyspecific antibodies. Supplemental Table 1 reviews antibodies clinically tested in AML (supplemental material available online with this article; https://doi.org/10.1172/JCI129204DS1).

Clinical development of unmodified mAbs targeting CD33, CD123, and several other antigens in AML, alone or in combination with chemotherapy, demonstrated limited clinical activity (122-124). Ongoing clinical studies are investigating BI836858, a CD33-targeting antibody with an $\mathrm{Fc}$ domain engineered to optimize interaction with the Fc receptor (CD16) on NK cells, in combination with HMAs or the immunocytokine F16-IL2 (teleukin) (125). In vitro studies suggest that decitabine may potentiate BI836858-mediated ADCC through upregulation of NKG2D ligands on leukemia cells (126). The mAb ARGX-110 targets CD70, which serves as a ligand for CD27 (TNF receptor), both of which are highly expressed on AML blasts and LSCs, but not normal HSCs. In murine xenograft models, decitabine upregulated CD70 expression on LSCs but not normal HSCs, and showed synergism with CD70 blockade (127). ARGX-110 in combination with azacitidine produced a high overall response rate (ORR) with no dose-limiting toxicities in early clinical testing (128). Promising clinical activity and tolerability were recently reported for magrolimab, an anti-CD47 antibody that promotes macrophage-mediated phagocytosis, when given in combination with azacitidine to newly diagnosed MDS and AML patients, including those carrying TP53 mutations (129).

Among ADCs, gemtuzumab ozogamicin (GO), a humanized anti-CD33 antibody conjugated to calicheamicin, was recently reapproved for treating newly diagnosed AML in adults, and relapsed/refractory $(\mathrm{R} / \mathrm{R}) \mathrm{AML}$ in adults and pediatric patients, after studies using lower or fractionated doses of GO in combination with chemotherapy demonstrated efficacy with limited toxicity (130-132). Patients with favorable-karyotype AML benefited the most from addition of GO to induction chemotherapy (133).
Encouraging safety and clinical activity in R/R AML and blastic plasmacytoid DC neoplasm (BPDCN) have also been recently reported for IMGN632, a CD123-targeting antibody coupled to the novel indolinobenzodiazepine payload (134). Additional ADCs targeting CD33, CD123, and CD135 (FLT3) and antibody radioimmunoconjugates targeting CD33 and CD45 continue in clinical testing, the latter mostly in the pretransplant setting because of concern for myelosuppression (Supplemental Table 1).

Multispecific antibodies are engineered to combine specificities of two or more antibodies in order to bind tumor cell antigens, activate Teffs or NK cells, and bring two cell types into proximity, maximizing a tumoricidal interaction. Prompted by the success of blinatumomab, a CD3xCD19 bispecific T cell engager (BiTE) antibody in ALL, several variants of bispecific or even trispecific antibodies targeting CD33, CD123, or CLL1 are being explored in trials in AML (Supplemental Table 1 and Figure 2). So far, clinical studies of bispecific antibodies in AML have not reproduced the efficacy seen in ALL, as summarized in Table 2. Several studies are still in the dose-escalation phase, but cytokine release syndrome (CRS) has occurred with all the constructs, requiring careful dose escalation and symptom management. Deeper understanding of differential responses among primary refractory and relapsed patients, as seen with flotetuzumab, including the role of immune-enriched $\mathrm{BM}$ microenvironment, which is characterized by higher IFN- $\gamma$ scores and tumor inflammation signature, will be critical to optimizing the activity of this approach and improving patient selection (135-138). Studies of bispecific antibodies in combination with PD-1 CPIs to overcome potential resistance mechanism are under way, and constructs integrating locally restricted blockade of the PD-1/PD-L1 checkpoint have been developed (139).

\section{Cenetically redirected T cells in AML}

Investigators have been actively seeking strategies to reproduce in AML the successful results obtained with anti-CD19 CAR T cells in lymphoid malignancies. However, these efforts have been hampered by the difficulty in identifying suitable targets, as discussed previously. Alternative strategies formulated to bypass this problem include (a) CAR T cells activating only in response to a combination of targets $(13,140)$; (b) use of non-persisting cell types or safety switches to eliminate CAR-modified cells after disease eradication $(141,142)$; and (c) genome editing of HSCs to generate a CAR-resistant hematopoiesis $(143,144)$.

A number of anti-CD33 CAR T cell constructs have in fact demonstrated robust preclinical efficacy against primary AML blasts both in vitro and in humanized animal models, accompanied by evidence of toxicity against leukemic and nonleukemic myeloid cells with, in part, conflicting results in terms of their effects on HSCs $(9,10,145,146)$. Clinical trials using anti-CD33 CAR T cells are ongoing or just completed (NCT03126864, NCT03971799, NCT02799680, NCT01864902; ClinicalTrials. gov), but to date, only one report has been published on a single patient with refractory AML who developed CRS and experienced transient BM blast reduction following infusion of autologous anti-CD33 CAR T cells (147).

Regarding anti-CD123 CAR T cells, a number of studies documented promising preclinical antileukemia activity, but at least one study raised concerns about toxicity toward HSCs (9, 11, 


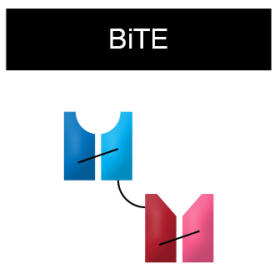

AMG 330 (CD3XCD33) AMG $673(\mathrm{CD} 3 \times \mathrm{CD} 33$ XmAb 14045 (CD3xCD123)

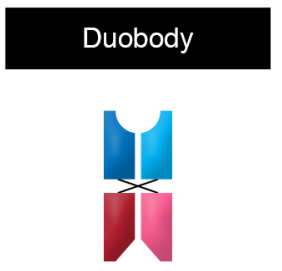

JNJ-63709178 (CD3XCD123) MCLA-117 (CD3XCLL-1)
DART

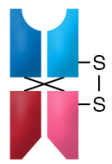

MGD006 (CD3XCD123)
Tandem diabody

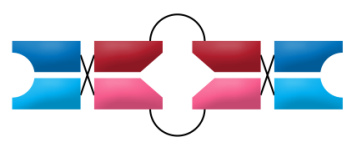

AMV-564 (CD3xCD33)

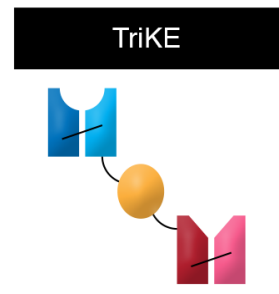

CD16xIL-15xCD33

Figure 2. Bispecific antibody formats. Schematic summary of some of the strategies that are being tested to link antigen-binding fragments (Fabs) of two or more monoclonal antibodies with different specificities. Under each construct are provided some examples of bispecifics of that class in advanced clinical development (see also Table 2).

148). Recently, an anti-CD123 CAR, MB-102, received the FDA's orphan drug designation for both AML and BPDCN based on initial results from an ongoing phase I study (NCT02159495). In the study, patients with AML and BPDCN demonstrated complete remissions (CRs) at low MB-102 doses without dose-limiting toxicities. An expansion phase of the MB-102 study is ongoing, together with a number of other clinical trials testing different anti-CD123 CAR T cell products (NCT04106076, NCT03190278).
Besides CD33 and CD123, other targets are being tested for CAR T cell development, including folate receptor $\beta$ (149), CLL1 (150), FLT3 (151), LeY (152), NKG2D ligands (153), CD70 (154), and CD44v6 (39). Clinical data regarding these approaches are scarce, limited to three AML patients treated with anti-LeY antigen CARs (155) and three early-phase studies on NKG2D-based CARs (156-158). No studies documented major toxicities, and some reported initial hints on efficacy.

\section{Table 2. Select reported studies with bispecific antibodies in AML}

\section{Antibody/study Target/construct}

AMC 330; $\quad$ CD3xCD33. BiTE, scBsTaFv (low molecular

phase I,

NCT02520427

(192)

AMC 673;

phase I,

NCT03224819

(195)

\section{AMV 564;}

phase I,

NCT03144245

(196)

Flotetuzumab;

phase $1 / 11$,

NCT02152956

$(136,137,197$

198) ells a PD-L1 on AML cells $(80,193,194)$.

\section{CD3xCD33. Half-life-extended BiTE}

(fused to the $\mathrm{N}$-terminus of a single-chain IgG Fc region)

\section{CD3xCD33. TandAbs.}

Preclinical: Cytotoxic against $\mathrm{CD} 33^{+} \mathrm{AML}$

cells in vitro and in $\mathrm{HL}-60$ xenograft

mouse model in vivo.

CD3xCD123. DART.
Treatment plan/eligibility

Administration: $\mathrm{Cl}$ 2-4

weeks on/1-4 weeks off.

Eligibility: Relapsed/

refractory adult AML. Eligibility: Relapsed/
refractory adult AML. weeks/4 weeks cycles. Eligibility: Relapsed/

Administration: 2 Short i.v. infusions over 2 weeks. Eligibility: Relapsed/ refractory adult AML.

\section{Administration: $500 \mathrm{ng} / \mathrm{kg} / \mathrm{d}$ Cl weeks 2-4 with lead-in dose in week 1 (cycle 1), and a 4-day on/3-day off schedule for cycle $2+$. \\ Eligibility: Early relapsed/ refractory adult AML patients.}

CD3xCD123. BiTE with a full-length lg molecule.

XmAb14045;

phase I, molecule.

(199)

Administration: Cl over 2

\section{Outcomes}

Enrollment: 40 Patients $/ 12$ cohorts (dose range, $0.5-480 \mu \mathrm{g} / \mathrm{d}$ ). Tolerated (target) dose: $240 \mu \mathrm{g} / \mathrm{d}$ with lead-in dose escalation.

Toxicity: Related SAE 43\%, most commonly CRS (28\%) and febrile neutropenia (18\%). Activity: 2 CR and 2 CRi at the target dose of $120-240 \mu \mathrm{g} / \mathrm{d}$.

Enrollment: 30 Patients/10 cohorts (dose range, 0.05-72 $\mu$ i.v. per dose); dose escalation continues.

Toxicity: Related SAE 50\%, most commonly elevated hepatic enzymes (17\%), CRS and leukopenia (13\%)

Activity: BM blast reduction in $44 \%$ of patients ( $22 \%$ of patients with $>50 \%$ reduction); 1 CRi. PD: Upregulation of CD25 and CD69 on T cell subsets, cytokine release at higher doses.

Enrollment: 36 Patients/ 10 cohorts (dose range, $0.5-300 \mu \mathrm{g} / \mathrm{d}$ ); dose escalation continues. Toxicity: $11 \% \geq$ Grade 3 anemia, no DLTs, no grade 3 CRS with lead-in dose escalation. Activity: BM blast reduction in 49\% of patients; 1 CR; 1 CRi; 1 PR; 3 patients with neutrophil improvement.

PD: T cell redistribution; increase in BM T cells with repeat cycles.

Enrollment: 50 Patients at RP2D.

Toxicity: $\geq$ Grade 3 CRS in primary refractory and relapsed patients was $3 \%$ and $16 \%$, respectively. Activity: $32 \%$ Response rate in 28 primary refractory patients (3 CR, 3 CRi, 3 CRh); no response in relapsed patients.

PD: Higher CD123 receptor density in CR patients compared with nonresponders; baseline immune gene signatures, including significantly higher IFN- $\gamma$ scores and tumor inflammation signature scores, correlated with flotetuzumab activity; increase in T cell infiltration and clustering around CD123 AML cells in the BM in responders; PD-L1 induction in nonresponders; baseline frequency of circulating $\mathrm{CD} 4^{+}$cells correlated with CRS severity.

Administration: Weekly Enrollment: 64 Patients (RP2D for flat weekly dosing $1.3 \mu \mathrm{g} / \mathrm{kg}$ ); dose escalation with administration, 4-week cycles. priming dose followed by increasing dose continues.

Eligibility: Relapsed/ Toxicity: $11 \% \geq$ Grade 3 CRS; febrile neutropenia and peripheral edema (30\%), elevated refractory adult AML, B-ALL, liver functions (19\%), pneumonia, stomatitis, hyperglycemia, sepsis. CML-BC, and BPDCN. Activity: 2 CR, 1 CRi at the highest doses (23\%).

B-ALL, B cell acute lymphoblastic leukemia; BiTE, bispecific T cell engager; BPDCN, blastic plasmacytoid DC neoplasm; Cl, continuous infusion; CML-BC, chronic myeloid leukemia-blast crisis; CR, complete remission; CRh, CR with partial hematologic recovery; CRi, CR with incomplete hematologic recovery; CRS, cytokine release syndrome; DART, dual-affinity retargeting molecule; DLT, dose-limiting toxicity; PD, parmacodynamic studies; PR, partial remission; RP2D, recommended phase II dose; SAE, serious adverse event(s). 
An alternative approach is represented by genetic engineering of T cells with a high-affinity $\mathrm{T}$ cell receptor (TCR) specific for a leukemia antigen. Although limited by the antigen HLA restriction and the efficiency of processing and presentation, this strategy can theoretically target a much wider antigen repertoire, including LAAs and neoantigens. To date, a number of preclinical studies have focused on redirecting T cells against WT1 $(159,160)$, which rapidly translated into clinical studies demonstrating no major toxicities, persistence over time of the infused lymphocytes, and encouraging signs of activity $(17,161,162)$. Alternative intracellular AML antigens for which TCR-based genetic redirection showed promising preclinical results include telomerase (163), RHAMM (164), and the mutated form of NPM1 (7).

\section{Vaccine strategies in AML}

Both peptide and DC-based vaccines against LAAs have been explored in AML to prime or boost leukemia-specific immune responses. WT1 peptide vaccination strategies appear to be safe with hints of clinical activity in terms of responses and survival outcomes in MDS/AML patients. Correlation between induction of WT1-specific T cells and reduction of WT1 mRNA levels was observed in different studies (165). A recent phase II trial of a multivalent WT1 peptide vaccine, galinpepimut-S, given to $22 \mathrm{AML}$ patients in first CR documented immunologic responses in $64 \%$ of patients, including increased $\mathrm{CD} 4^{+} \mathrm{T}$ cell proliferation, $\mathrm{CD} 8^{+} \mathrm{T}$ cell IFN- $\gamma$ secretion, and frequency of WT1-specific CD8 ${ }^{+} \mathrm{T}$ cells. Immunologic response but not baseline WT1 levels appeared to correlate with improved survival outcomes (166).

Different DC-based strategies, including AML-DCs, monocytic DCs, or hybridomas, have been explored. While AML-DCs have the advantage of expressing a full spectrum of antigens, monocytic DCs were more effective in activating autologous antileukemia $\mathrm{T}$ cell responses (reviewed in ref. 167). The allogeneic DC vaccine DCP-001, developed from an AML-derived cell line, given to 12 AML patients resulted in median OS of 36 months from the start of vaccination in patients lacking circulating blasts. Long-term survival correlated with maintained $\mathrm{T}$ cell levels and induction of multifunctional immune responses (168). In a phase II study, DCs electroporated with WT1 mRNA were given as a post-remission treatment to 30 patients with AML at high risk of relapse; 9 patients achieved molecular remission (5 still in remission after median follow-up of 9 years), and 4 patients achieved disease stabilization. Long-term clinical response correlated with the induction of WT1-specific CD8 ${ }^{+} \mathrm{T}$ cell response (18). This approach is being tested in a randomized clinical study in the post-remission setting (WIDEA; NCT01686334). Interesting data have been published on the use of personalized vaccine with a hybridoma of AML cells and autologous patient-derived DCs. Among 17 patients vaccinated in CR after chemotherapy, 12 (71\%) remain in remission at a median follow-up of 57 months. Vaccination was associated with expansion of leukemia-specific T cells against MUC1, WT1, and NY-EOS antigens that lasted more than 6 months (19, 169). The multicenter study exploring this approach is ongoing (NCT01096602). Research efforts to optimize immunostimulatory properties of DCs, such as use of IL-15-differentiated DCs, and combining DCs with CPIs or HMA continue. A more personalized approach using multi-epitope neoantigen vaccination was proven feasible not only in tumors with high mutational load such as melanoma (170), but also in glioblastoma (171), which typically has a low mutation load, raising the possibility of exploring a similar approach in AML. A clinical trial based on ex vivo enrichment and subsequent reinfusion of $\mathrm{T}$ cells specific for patient neoantigens recently started accrual in high-risk MDS (172).

\section{Checkpoint inhibitors in AML}

Studies of CPIs in AML are listed in Supplemental Table 2, and select reported studies are summarized in Table 3. With the hope that CTLA4 blockade would reactivate alloreactive T cells, early studies explored ipilimumab in hematologic malignancies in the setting of post-alloHSCT disease progression (173, 174). Ipilimumab at $10 \mathrm{mg} / \mathrm{kg}$ dose produced promising responses in 5 of 12 AML patients, 4 with extramedullary leukemia, with 3 responses lasting more than 1 year. Responses were accompanied by in situ infiltration of cytotoxic $\mathrm{CD}^{+} \mathrm{T}$ cells, decreased systemic Treg activation, and expanded Teff subpopulations in PB (174). In contrast, nontransplanted MDS patients who failed HMAs only tolerated ipilimumab at $3 \mathrm{mg} / \mathrm{kg}$, a dose displaying limited clinical activity. Patients benefiting from therapy had a higher frequency of $\mathrm{T}$ cells expressing ICOS after treatment compared with nonresponders (175). Ipilimumab in combination with decitabine is being explored in an ongoing phase I study, in both pre- and postalloHSCT settings, with early hints of clinical activity, particularly in nontransplanted R/R AML patients (176).

Given the multiple immune effects of HMAs, their clinical testing in combination with PD-1/PD-L1 pathway inhibition has been pursued in several studies in AML (Table 3). Nivolumab given in combination with azacitidine to 70 older, heavily pretreated AML patients yielded an ORR of $33 \%$, with a higher ORR of $58 \%$ in HMA-naive patients. The median OS of 6.3 months compared favorably with historical controls treated with azacitidine alone at the same institution. Higher percentages of $\mathrm{CD}^{+}$and $\mathrm{CD}^{+}$ cells in pretherapy $\mathrm{BM}$ and $\mathrm{CD}^{+}$cells in $\mathrm{PB}$ were predictive of response, whereas upregulation of CTLA4 on $\mathrm{CD} 4^{+}$Teffs after treatment was observed in nonresponders, indicating a potential resistance mechanism (62). On the basis of this observation, azacitidine and nivolumab were combined with ipilimumab in a subsequent cohort of 31 patients, and produced an improved ORR of $44 \%$ and median OS of 10.5 months, but at the expense of more frequent immune-related adverse events (177).

Combinations of another PD-1-blocking antibody, pembrolizumab, with decitabine or azacitidine produced similar response and survival data to those observed with azacitidine and nivolumab in R/R AML patients $(178,179)$. Early reports from both azacitidine/nivolumab and azacitidine/pembrolizumab studies suggested encouraging ORR and survival among small cohorts of newly diagnosed and unfit older AML patients $(179,180)$. However, a randomized phase II study of azacitidine plus durvalumab (antiPD-L1) versus azacitidine alone in 214 untreated high-risk MDS and AML patients reported safety but no additional efficacy for the combination (181). Whether upregulation of PD-L2 on leukemia cells following PD-L1 inhibition may influence activity of PD-L1 versus PD-1 inhibition in this setting requires further studies (182).

PD-1/PD-L1 pathway inhibition in combination with chemotherapy was also found to be feasible in both newly diagnosed 


\section{Table 3. Select reported studies of checkpoint inhibitors in combination with HMAs and chemotherapy in AML}

\begin{tabular}{|c|c|c|}
\hline Study & Agents & Population \\
\hline $\begin{array}{l}\text { Phase I/lb, } \\
\text { NCT01822509 } \\
\text { (174) }\end{array}$ & $\begin{array}{l}\text { Ipilimumab }(3 \mathrm{mg} / \mathrm{kg} \\
\text { or } 10 \mathrm{mg} / \mathrm{kg} \text { every } 3 \\
\text { weeks } \times 4 \text { then every } \\
12 \text { weeks } \times 4 \text { ) }\end{array}$ & $\begin{array}{l}28 \text { patients (12 AML) } \\
\text { relapsed hematologic } \\
\text { malignancies after } \\
\text { alloHSCT }\end{array}$ \\
\hline $\begin{array}{l}\text { Phase II, } \\
\text { NCTO2397720: } \\
\text { Cohort } 1 \text { (62) }\end{array}$ & $\begin{array}{l}\text { Nivolumab ( } 3 \mathrm{mg} / \mathrm{kg} \\
\text { every } 2 \text { weeks) plus } \\
\text { azacitidine }\end{array}$ & $\begin{array}{l}70 \mathrm{R} / \mathrm{R} \text { AML patients } \\
\text { (median age, } 70 \mathrm{yr} \text { ) }\end{array}$ \\
\hline Cohort 2 (177) & $\begin{array}{l}\text { Nivolumab plus } \\
\text { ipilimumab (1 } \mathrm{mg} / \mathrm{kg} \\
\text { every } 6 \text { weeks) plus } \\
\text { azacitidine }\end{array}$ & $\begin{array}{l}31 \mathrm{R} / \mathrm{R} \text { AML patients } \\
\text { (median age, } 71 \mathrm{yr} \text { ) }\end{array}$ \\
\hline $\begin{array}{l}\text { Phase I/II, } \\
\text { NCT02996474 } \\
(178)\end{array}$ & $\begin{array}{l}\text { Pembrolizumab ( } 200 \\
\text { mg every } 3 \text { weeks) } \\
\text { plus decitabine }\end{array}$ & $\begin{array}{l}10 \mathrm{R} / \mathrm{R} \text { AML patients } \\
\text { (median age, } 62 \mathrm{yr} \text { ) }\end{array}$ \\
\hline $\begin{array}{l}\text { Phase II, } \\
\text { NCT02845297 } \\
\text { (179) }\end{array}$ & $\begin{array}{l}\text { Pembrolizumab ( } 200 \\
\text { mg every } 3 \text { weeks) } \\
\text { plus azacitidine }\end{array}$ & $\begin{array}{l}37 \text { R/R (Cohort 1); } 22 \\
\text { newly diagnosed, old, } \\
\text { unfit (Cohort 2) AML } \\
\text { patients }\end{array}$ \\
\hline
\end{tabular}

Phase ll, NCT02464657 every 2 weeks) plus (183) cytarabine/idarubicin

$\begin{array}{lll}\begin{array}{l}\text { Phase II, } \\ \text { NCT02768792 }\end{array} & \begin{array}{l}\text { Pembrolizumab (200 } \\ \text { mg every 3 weeks) }\end{array} & \begin{array}{l}\text { 37 R/R AML patients } \\ \text { (median age, 54 yr) }\end{array} \\ \text { (185) } & \text { plus HiDAC } & \end{array}$

$\begin{array}{lll}\text { Phase II, } & \text { Durvalumab (1000 } & \text { Untreated 214 } \\ \text { randomized, } & \text { mg every 4 weeks) } & \text { patients: MDS (84) } \\ \text { NCT02775903 } & \text { plus azacitidine (Arm } & \text { and AML (129) old, } \\ \text { (181) } & \begin{array}{l}\text { A) versus azacitidine } \\ \text { (Arm B) }\end{array} & \text { unfit patients } \\ & \text { (Arm B } & \end{array}$

Phase IB, MBG453, anti-TIM3 NCT03066648 Ab (240-800 mg (200) every 2 weeks) plus decitabine

44 Newly diagnosed AML, high-risk MDS patients (median age, $54 \mathrm{yr})$ (median age, $70 \mathrm{yr}$ )

\section{Outcomes}

Toxicity: $21 \%$ irAEs, including 1 death; $14 \%$ GVHD precluding

further ipilimumab administration.

Activity: No response at $3 \mathrm{mg} / \mathrm{kg} ; 59 \%$ patients responded, with $23 \%$ CR at $10 \mathrm{mg} / \mathrm{kg} ; 5 / 12 \mathrm{AML}$ patients with CR, 4 having EMD.

Toxicity: 11\% $\geq$ Grade 3 irAEs; 2 (3\%) irAE-related deaths,

$11 \%$ 8-week mortality.

Activity: ORR 33\% with 22\% CR/CRi; ORR higher in HMA-naive vs. HMA-pretreated patients ( $58 \%$ vs. $22 \%$ ); median OS, 6.3 months.

Toxicity: 25\% $\geq$ Grade 3 irAEs; no irAE-related death; 8\% 8-week mortality.

Activity: ORR 44\% with 36\% CR/CRi in 24 evaluable patients; median 0510.5 months.

Toxicity: No grade $5 \mathrm{AEs}$.

Activity: ORR 20\%; median OS 7 months.

Toxicity: Cohort 1 (median age, $65 \mathrm{yr}$ ): $24 \% \geq$ Grade 3 irAEs;

13\% 8-week mortality; Cohort 2: 14\% $\geq$ Grade 3 irAEs; $9 \%$

8-week mortality.

Activity: Cohort 1 (median age, 75 yr): ORR $32 \%$ with $14 \%$ CR/CRi among 29 evaluable patients; median 0 S 10.8 months; Cohort 2 : ORR $71 \%$ with $47 \%$ CR/CRi among 17 evaluable patients; median OS 13.1 months.

Toxicity: $14 \% \geq$ Grade 3 irAEs; grade 3-4 GVHD occurred in $26 \%$ of patients who proceeded to alloHSCT; no nivolumab-related deaths. Activity: ORR $80 \%$ with $78 \%$ CR/CRi; 53\% MRD-negative CR after induction, $79 \%$ with subsequent therapy; median follow-up 17.25 months, EFS not reached, median RFS and OS both 18.54 months.

Toxicity: $14 \%$ > Grade 3 irAEs; 3\% 8-week mortality; $24 \%$ of patients received subsequent alloHSCT without significant CVHD. Activity: ORR $46 \%$ with $38 \%$ CR/CRi; median follow-up 7.8 months, median OS 8.9 months, and median DFS 5.7 months.

Toxicity: No safety signal; $17 \%$ and $27 \%$ irAEs in MDS and AML cohort, respectively, all resolved.

Activity: MDS: Arm A: ORR 62\%, CR 7\%, median 0S 11.6 months, versus Arm B: ORR 48\%, CR 9.5\%, median 0S 16.7 months; AML: Arm A: ORR 31\%, CR 17\%, median OS 13 months, versus Arm B: ORR 35\%, CR 21.5\%, median OS 14.4 months.

HR-MDS (17), CMML Toxicity: No MTD, 7\% > grade 3 irAEs, no treatment-related deaths. (4), and untreated or Activity: HR-MDS: $50 \%$ mCR/CR; newly diagnosed AML: $29 \%$ R/R AML (38) patients CRi; R/R AML: 29\% PR/CR; all patients with HR-MDS maintained

\section{Pharmacodynamics/notes}

Responses associated with in situ $C D 8^{+} T$ cell infiltration, expansion of PB Teff subpopulations, decreased Treg activation

Predictors of response: Pretherapy $\mathrm{BM} \mathrm{CD}^{+}$and $\mathrm{CD} 8^{+}$cells with optimal cutoffs of $>13.2 \%$ and $>4.01 \%$, respectively; and $\mathrm{PBC} \mathrm{CD}^{+}$with cutoff $>20.5 \%$

Survival compares favorably with nivolumab/ azacitidine (6.3 months) and contemporary historical HMA-based trials at MD Anderson Cancer Center (4.6 months)
At baseline, BM of nonresponders had significantly higher percentages of $\mathrm{CD} 4^{+}$Teffs coexpressing PD-1 and TIM3

Increased expression of innate immune genes by blasts and of cell cycle genes by the nonblast fraction before treatment correlated with response to therapy; CR was associated with increased measures of $B$ and $T$ cell diversity

$A E$, adverse event; CMML, chronic myelomonocytic leukemia; CR, complete remission; CRi, CR with incomplete hematologic recovery; DFS, disease free survival; EFS, event free survival; EMD, extramedullary disease; GVHD, graft-versus-host disease; HiDAC, high dose cytarabine; HMA, hypomethylating agent; HR-MDS, high-risk myelodysplasia; irAE, immune-related adverse event; mCR, marrow CR; MDS, myelodysplasia; MRD, measurable residual disease; MTD, maximum tolerated dose; ORR, overall response rate; OS, overall survival; PR, partial remission; RFS, relapse free survival; R/R, relapsed/refractory.

and R/R AML. Nivolumab in combination with induction cytarabine plus idarubicin produced an ORR of $80 \%$ and median OS of 18.54 months in untreated, younger AML patients, but $26 \%$ of patients who proceeded to alloHSCT developed grade 3-4 graftversus-host disease. Higher percentages of $\mathrm{CD}^{+}{ }^{+}$Teffs coexpressing PD-1 and TIM3 in pretreatment BM were observed in nonresponders to therapy (183). In R/R AML patients, pembrolizumab with high-dose cytarabine yielded an ORR of $46 \%$ and median OS of 8.9 months, without significant graft-versus-host disease in patients subsequently receiving alloHSCT $(184,185)$. Randomized studies with CPIs are ongoing (NCT03092674; SWOG 1612) as well as intense search for biomarkers of response. Pretreatment BM T cell infiltration and measurements of T cell functionality appear promising in predicting response to CPIs and HMAs, and should be examined prospectively to improve patient selection and limit toxicities (177). 
Single-agent PD-1 inhibition was also explored in the setting of minimal residual disease following chemotherapy or alloHSCT $(186,187)$. In the post-alloHSCT relapse setting, reports from several small studies suggest limited single-agent PD-1 inhibitor activity and safety concerns (188-190). Recent reports suggest that different transplant platforms, such as post-transplant cyclophosphamide, may be associated with less toxicity, and additional studies are required (191). Moreover, recent recognition that AML cells may exploit HLA class II downregulation versus immune checkpoint upregulation as alternative modalities to avoid recognition by donor-derived $\mathrm{T}$ cells could provide an opportunity to differentiate patients with post-transplant relapse who are more or less likely to benefit from CPIs (54).

\section{Conclusion}

While impressive progress has been made in the molecular understanding of tumor immunology and clinical application of immunomodulatory agents in recent years, we still must learn how to effectively incorporate different immunotherapeutic strategies in AML. In general, the efforts to improve delivery of diverse immune strategies with the goal of harnessing the full power of the immune system against AML cells have been hampered by host and disease heterogeneity, and complicated by the immunoevasive capabilities of AML blasts. The inherent genetic, epigenetic, and clonal complexity of this disease also continues to challenge identification of the best predictors of response to different immunotherapeutic interventions. Novel strategies need to be carefully integrated with standard chemotherapy as well as with alloHSCT and moved to less advanced or upfront therapeutic settings. Early identification of resistance mechanisms, both extrinsic and intrinsic, and development of strategies to overcome them will be crucial endeavors for improving the immunotherapeutic armamentarium against AML. Ultimately, the successful application of immunotherapy will depend on thorough mechanistic understanding of the immunologic, genomic, and microenvironmental complexity of AML, informing data-driven design of rational combination approaches.

\section{Acknowledgments}

The authors thank Cristina Toffalori for help in drafting the manuscript figures and Judith E. Karp for critical reading of the manuscript. LV acknowledges support from the Italian Ministry of Health (RF2011-02351998, RF-2011-02348034, and TRANSCAN HLALOSS), the Associazione Italiana per la Ricerca sul Cancro (Start-Up Grant 14162 and IG 22197), and the DKMS Mechtild Harf Foundation (DKMS Mechtild Harf Research Grant 2015). IG acknowledges support from the NIH (UM1-CA186691 and P30-CA006973).

Address correspondence to: Luca Vago, Unit of Immunogenetics, Leukemia Genomics and Immunobiology, IRCCS San Raffaele Scientific Institute, via Olgettina, 60, Milano, 20132, Italy. Phone: 390226434341; Email: vago.luca@hsr.it. Or to: Ivana Gojo, Johns Hopkins Sidney Kimmel Comprehensive Cancer Center, CRB1; Room 346, 1650 Orleans Street, Baltimore, Maryland 21287, USA. Phone: 410.502.8775; Email: igojo1@jhmi.edu.
1. Döhner H, Weisdorf DJ, Bloomfield CD. Acute myeloid leukemia. N Engl JMed. 2015;373(12):1136-1152.

2. Passweg JR, et al. The EBMT activity survey report 2017: a focus on allogeneic HCT for nonmalignant indications and on the use of nonHCT cell therapies. Bone Marrow Transplant. 2019;54(10):1575-1585.

3. D'Souza A, Fretham C. Current uses and outcomes of hematopoietic cell transplantation (HCT): Center for International Blood \& Marrow Transplant Research (CIBMTR) Summary Slides, 2018. http://www.cibmtr.org/ReferenceCenter/ SlidesReports/SummarySlides/Documents. Updated February 18, 2019. Accessed February 20, 2020.

4. Stern M, et al. Sensitivity of hematological malignancies to graft-versus-host effects: an EBMT megafile analysis. Leukemia. 2014;28(11):2235-2240.

5 . Walter RB, et al. Impact of pretransplantation minimal residual disease, as detected by multiparametric flow cytometry, on outcome of myeloablative hematopoietic cell transplantation for acute myeloid leukemia. JClin Oncol. 2011;29(9):1190-1197.

6. Inoue $\mathrm{K}$, et al. Aberrant overexpression of the Wilms tumor gene (WT1) in human leukemia. Blood. 1997;89(4):1405-1412.

7. van der Lee DI, et al. Mutated nucleophosmin 1 as immunotherapy target in acute myeloid leukemia. J Clin Invest. 2019;129(2):774-785.

8. Anguille S, Van Tendeloo VF, Berneman ZN. Leukemia-associated antigens and their relevance to the immunotherapy of acute myeloid leukemia. Leukemia. 2012;26(10):2186-2196.

9. Pizzitola I, et al. Chimeric antigen receptors against CD33/CD123 antigens efficiently target primary acute myeloid leukemia cells in vivo. Leukemia. 2014;28(8):1596-1605.

10. Kenderian SS, et al. CD33-specific chimeric antigen receptor $\mathrm{T}$ cells exhibit potent preclinical activity against human acute myeloid leukemia. Leukemia. 2015;29(8):1637-1647.

11. Gill S, et al. Preclinical targeting of human acute myeloid leukemia and myeloablation using chimeric antigen receptor-modified T cells. Blood. 2014;123(15):2343-2354.

12. Perna F, et al. Integrating proteomics and transcriptomics for systematic combinatorial chimeric antigen receptor therapy of AML. Cancer Cell. 2017;32(4):506-519.e5.

13. Haubner S, et al. Coexpression profile of leukemic stem cell markers for combinatorial targeted therapy in AML. Leukemia. 2019;33(1):64-74.

14. Goswami M, et al. Expression of putative targets of immunotherapy in acute myeloid leukemia and healthy tissues. Leukemia. 2014;28(5):1167-1170.

15. Siegel S, et al. Induction of cytotoxic T-cell responses against the oncofetal antigen-immature laminin receptor for the treatment of hematologic malignancies. Blood. 2003;102(13):4416-4423.

16. Cilloni D, et al. Usefulness of quantitative assessment of the WT1 gene transcript as a marker for minimal residual disease detection. Blood. 2003;102(2):773-774.

17. Chapuis AG, et al. T cell receptor gene therapy targeting WT1 prevents acute myeloid leukemia relapse post-transplant. Nat Med. 2019;25(7):1064-1072.

18. Anguille S, et al. Dendritic cell vaccination as postremission treatment to prevent or delay relapse in acute myeloid leukemia. Blood. 2017;130(15):1713-1721.

19. Rosenblatt J, et al. Individualized vaccination of AML patients in remission is associated with induction of antileukemia immunity and prolonged remissions. Sci Transl Med. 2016;8(368):368ra171.

20. Rezvani K, et al. Leukemia-associated antigen-specific T-cell responses following combined PR1 and WT1 peptide vaccination in patients with myeloid malignancies. Blood. 2008;111(1):236-242.

21. Qazilbash MH, et al. Vaccination with the PR1 leukemia-associated antigen can induce complete remission in patients with myeloid leukemia. Blood. 2004;104(11):259.

22. Arai J, Yasukawa M, Ohminami H, Kakimoto M, Hasegawa A, Fujita S. Identification of human telomerase reverse transcriptase-derived peptides that induce HLA-A24-restricted antileukemia cytotoxic T lymphocytes. Blood. 2001;97(9):2903-2907.

23. DiPersio JF, et al. Immune responses in AML patients following vaccination with GRNVAC1, autologous RNA transfected dendritic cells expressing telomerase catalytic subunit hTERT. Blood. 2009;114(22):633.

24. Rezvani K, et al. Ex vivo characterization of polyclonal memory CD8+ T-cell responses to PRAME-specific peptides in patients with acute 
lymphoblastic leukemia and acute and chronic myeloid leukemia. Blood. 2009;113(10):2245-2255.

25. Li L, et al. Immunotherapy for patients with acute myeloid leukemia using autologous dendritic cells generated from leukemic blasts. Int JOncol. 2006;28(4):855-861.

26. Bigalke I, et al. AML patients in minimal residual disease vaccinated with a novel generation of fast dendritic cells expressing WT- 1 and PRAME mount specific immune responses that relate to clinical outcome. Blood. 2015;126(23):3798.

27. Falkenburg JHF, Jedema I. Graft versus tumor effects and why people relapse. Hematology Am Soc Hematol Educ Program. 2017;2017(1):693-698.

28. Alexandrov LB, et al. Signatures of mutational processes in human cancer. Nature. 2013;500(7463):415-421.

29. Gilboa E. The makings of a tumor rejection antigen. Immunity. 1999;11(3):263-270.

30. Schumacher TN, Schreiber RD. Neoantigens in cancer immunotherapy. Science. 2015;348(6230):69-74.

31. Penter L, Wu CJ. Personal tumor antigens in blood malignancies: genomics-directed identification and targeting. JClin Invest. 2020;130(4):1595-1607.

32. Greiner J, et al. Mutated regions of nucleophosmin 1 elicit both CD4(+) and CD8(+) T-cell responses in patients with acute myeloid leukemia. Blood. 2012;120(6):1282-1289.

33. Schumacher T, et al. A vaccine targeting mutant IDH1 induces antitumour immunity. Nature. 2014;512(7514):324-327.

34. Deniger DC, et al. T-cell responses to TP53 "hotspot" mutations and unique neoantigens expressed by human ovarian cancers. Clin Cancer Res. 2018;24(22):5562-5573.

35. Rutella $S$, et al. Immune infiltration correlates with TP53 mutational status in a multi-cohort acute myeloid leukemia study. Poster presented at: Society for Immunotherapy of Cancer 2019; November 6-10, 2019; National Harbor, MD.

36. Dong ZY, et al. Potential predictive value of TP53 and KRAS mutation status for response to PD-1 blockade immunotherapy in lung adenocarcinoma. Clin Cancer Res. 2017;23(12):3012-3024.

37. Biton J, et al. TP53, STK11, and EGFR mutations predict tumor immune profile and the response to anti-PD-1 in lung adenocarcinoma. Clin Cancer Res. 2018;24(22):5710-5723.

38. Adamia S, et al. NOTCH2 and FLT3 gene mis-splicings are common events in patients with acute myeloid leukemia (AML): new potential targets in AML. Blood. 2014;123(18):2816-2825.

39. Casucci M, et al. CD44v6-targeted T cells mediate potent antitumor effects against acute myeloid leukemia and multiple myeloma. Blood. 2013;122(20):3461-3472.

40. Cobbold M, et al. MHC class I-associated phosphopeptides are the targets of memorylike immunity in leukemia. Sci Transl Med. 2013;5(203):203ra125.

41. Lepore M, et al. A novel self-lipid antigen targets human T cells against CD1c(+) leukemias. JExp Med. 2014;211(7):1363-1377.

42. O'Donnell JS, Teng MWL, Smyth MJ. Cancer immunoediting and resistance to $\mathrm{T}$ cellbased immunotherapy. Nat Rev Clin Oncol.
2019;16(3):151-167.

43. Kolb HJ. Graft-versus-leukemia effects of transplantation and donor lymphocytes. Blood. 2008;112(12):4371-4383.

44. Salman A, et al. Determining the quantitative principles of $\mathrm{T}$ cell response to antigenic disparity in stem cell transplantation. Front Immunol. 2018;9:2284.

45. Lansford JL, et al. Computational modeling and confirmation of leukemia-associated minor histocompatibility antigens. Blood $A d v$. 2018;2(16):2052-2062.

46. Felix NJ, Allen PM. Specificity of T-cell alloreactivity. Nat Rev Immunol. 2007;7(12):942-953.

47. Knaus HA, et al. Signatures of CD8+ T cell dysfunction in AML patients and their reversibility with response to chemotherapy. JCI Insight. 2018;3(21):120974.

48. Knaus HA, Kanakry CG, Luznik L, Gojo I. Immunomodulatory drugs: immune checkpoint agents in acute leukemia. Curr Drug Targets. 2017;18(3):315-331.

49. Zeiser R, Vago L. Mechanisms of immune escape after allogeneic hematopoietic cell transplantation. Blood. 2019;133(12):1290-1297.

50. Vago L, et al. Loss of mismatched HLA in leukemia after stem-cell transplantation. $N$ Engl J Med. 2009;361(5):478-488.

51. Crucitti L, et al. Incidence, risk factors and clinical outcome of leukemia relapses with loss of the mismatched HLA after partially incompatible hematopoietic stem cell transplantation. Leukemia. 2015;29(5):1143-1152.

52. McCurdy SR, et al. Loss of the mismatched human leukocyte antigen haplotype in two acute myelogenous leukemia relapses after haploidentical bone marrow transplantation with post-transplantation cyclophosphamide. Leukemia. 2016;30(10):2102-2106.

53. Christopher MJ, et al. Immune escape of relapsed AML cells after allogeneic transplantation. N Engl J Med. 2018;379(24):2330-2341.

54. Toffalori C, et al. Immune signature drives leukemia escape and relapse after hematopoietic cell transplantation. Nat Med. 2019;25(4):603-611.

55. Kline DE, MacNabb BW, Chen X, Chan WC, Fosco D, Kline J. CD $8 \alpha^{+}$dendritic cells dictate leukemia-specific $\mathrm{CD} 8^{+} \mathrm{T}$ cell fates. JImmunol. 2018;201(12):3759-3769.

56. Zhang L, et al. CD40 ligation reverses $\mathrm{T}$ cell tolerance in acute myeloid leukemia. JClin Invest. 2013;123(5):1999-2010.

57. Xiao W, et al. Loss of plasmacytoid dendritic cell differentiation is highly predictive for post-induction measurable residual disease and inferior outcomes in acute myeloid leukemia. Haematologica. 2019;104(7):1378-1387.

58. Le Dieu R, et al. Peripheral blood T cells in acute myeloid leukemia (AML) patients at diagnosis have abnormal phenotype and genotype and form defective immune synapses with AML blasts. Blood. 2009;114(18):3909-3916.

59. Williams P, et al. The distribution of T-cell subsets and the expression of immune checkpoint receptors and ligands in patients with newly diagnosed and relapsed acute myeloid leukemia. Cancer. 2019;125(9):1470-1481.

60. Ismail MM, Abdulateef NAB. Bone marrow
T-cell percentage: a novel prognostic indicator in acute myeloid leukemia. Int J Hematol. 2017;105(4):453-464.

61. Behl D, et al. Absolute lymphocyte count recovery after induction chemotherapy predicts superior survival in acute myelogenous leukemia. Leukemia. 2006;20(1):29-34.

62. Daver N, et al. Efficacy, safety, and biomarkers of response to azacitidine and nivolumab in relapsed/refractory acute myeloid leukemia: a nonrandomized, open-label, phase II study. Cancer Discov. 2019;9(3):370-383.

63. Zhou Q, et al. Program death-1 signaling and regulatory $\mathrm{T}$ cells collaborate to resist the function of adoptively transferred cytotoxic $\mathrm{T}$ lymphocytes in advanced acute myeloid leukemia. Blood. 2010;116(14):2484-2493.

64. Zhou Q, et al. Coexpression of Tim-3 and PD-1 identifies a CD8+ T-cell exhaustion phenotype in mice with disseminated acute myelogenous leukemia. Blood. 2011;117(17):4501-4510.

65. Schnorfeil FM, et al. T cells are functionally not impaired in AML: increased PD-1 expression is only seen at time of relapse and correlates with a shift towards the memory $\mathrm{T}$ cell compartment. JHematol Oncol. 2015;8:93.

66. Jia B, et al. Bone marrow $\mathrm{CD} 8 \mathrm{~T}$ cells express high frequency of PD-1 and exhibit reduced anti-leukemia response in newly diagnosed AML patients. Blood Cancer J. 2018;8(3):34.

67. Dama P, Tang M, Fulton N, Kline J, Liu H. Gal9/ Tim-3 expression level is higher in AML patients who fail chemotherapy. J Immunother Cancer. 2019;7(1):175.

68. Tan J, et al. Higher PD-1 expression concurrent with exhausted CD8+ T cells in patients with de novo acute myeloid leukemia. Chin J Cancer Res. 2017;29(5):463-470.

69. Kong Y, et al. PD-1(hi)TIM-3(+) T cells associate with and predict leukemia relapse in AML patients post allogeneic stem cell transplantation. Blood Cancer J. 2015;5:e330.

70. Kong Y, et al. T-Cell immunoglobulin and ITIM domain (TIGIT) associates with CD8+ T-cell exhaustion and poor clinical outcome in AML patients. Clin Cancer Res. 2016;22(12):3057-3066

71. Radpour R, Riether C, Simillion C, Höpner S, Bruggmann R, Ochsenbein AF. CD $8^{+} \mathrm{T}$ cells expand stem and progenitor cells in favorable but not adverse risk acute myeloid leukemia. Leukemia. 2019;33(10):2379-2392.

72. Zajac M, Zaleska J, Dolnik A, Bullinger L, Giannopoulos K. Expression of CD274 (PD-L1) is associated with unfavourable recurrent mutations in AML. Br J Haematol. 2018;183(5):822-825.

73. Brodská B, Otevřelová P, Šálek C, Fuchs O, Gašová Z, Kuželová K. High PD-L1 expression predicts for worse outcome of leukemia patients with concomitant NPM1 and FLT3 mutations. Int JMol Sci. 2019;20(11):E2823.

74. Chen X, Liu S, Wang L, Zhang W, Ji Y, Ma X. Clinical significance of B7-H1 (PD-L1) expression in human acute leukemia. Cancer Biol Ther 2008;7(5):622-627.

75. Salih HR, et al. The role of leukemia-derived B7-H1 (PD-L1) in tumor-T-cell interactions in humans. Exp Hematol. 2006;34(7):888-894.

76. Norde WJ, et al. PD-1/PD-L1 interactions 
contribute to functional T-cell impairment in patients who relapse with cancer after allogeneic stem cell transplantation. Cancer Res. 2011;71(15):5111-5122.

77. Berthon C, et al. In acute myeloid leukemia, B7-H1 (PD-L1) protection of blasts from cytotoxic $T$ cells is induced by TLR ligands and interferon-gamma and can be reversed using MEK inhibitors. Cancer Immunol Immunother. 2010;59(12):1839-1849.

78. Krönig $\mathrm{H}$, et al. Interferon-induced programmed death-ligand 1 (PD-L1/B7-H1) expression increases on human acute myeloid leukemia blast cells during treatment. Eur J Haematol. 2014;92(3):195-203.

79. Yoyen-Ermis D, et al. Myeloid maturation potentiates STAT3-mediated atypical IFN- $\gamma$ signaling and upregulation of PD-1 ligands in AML and MDS. Sci Rep. 2019;9(1):11697.

80. Krupka C, et al. Blockade of the PD-1/PD-L1 axis augments lysis of AML cells by the CD33/CD3 BiTE antibody construct AMG 330: reversing a T-cell-induced immune escape mechanism. Leukemia. 2016;30(2):484-491.

81. Laszlo GS, Gudgeon CJ, Harrington KH, Walter RB. T-cell ligands modulate the cytolytic activity of the CD33/CD3 BiTE antibody construct, AMG 330. Blood Cancer J. 2015;5:e340.

82. Rettig MP, et al. Preliminary translational results from an ongoing phase 1 study of flotetuzumab, a CD123 x CD3 DART ${ }^{\circledast}$, in AML/MDS: rationale for combining flotetuzumab and anti-PD-1/PD-L1 immunotherapies. Blood. 2017;130(suppl 1):1365.

83. Aurelius J, et al. Monocytic AML cells inactivate antileukemic lymphocytes: role of NADPH oxidase/gp91(phox) expression and the PARP-1/PAR pathway of apoptosis. Blood. 2012;119(24):5832-5837.

84. Stringaris K, et al. Leukemia-induced phenotypic and functional defects in natural killer cells predict failure to achieve remission in acute myeloid leukemia. Haematologica. 2014;99(5):836-847.

85. Fauriat $\mathrm{C}$, et al. Deficient expression of NCR in NK cells from acute myeloid leukemia: Evolution during leukemia treatment and impact of leukemia cells in NCRdull phenotype induction. Blood. 2007;109(1):323-330.

86. Elias S, et al. Immune evasion by oncogenic proteins of acute myeloid leukemia. Blood. 2014;123(10):1535-1543.

87. Ustun C, Miller JS, Munn DH, Weisdorf DJ, Blazar BR. Regulatory $\mathrm{T}$ cells in acute myelogenous leukemia: is it time for immunomodulation? Blood. 2011;118(19):5084-5095.

88. Szczepanski MJ, et al. Increased frequency and suppression by regulatory $\mathrm{T}$ cells in patients with acute myelogenous leukemia. Clin Cancer Res. 2009;15(10):3325-3332.

89. Delia M, Carluccio P, Mestice A, Brunetti C, Albano F, Specchia G. Impact of bone marrow aspirate Tregs on the response rate of younger newly diagnosed acute myeloid leukemia patients. J Immunol Res. 2018;2018:9325261.

90. Curti A, Trabanelli S, Salvestrini V, Baccarani M, Lemoli RM. The role of indoleamine 2,3-dioxygenase in the induction of immune tolerance: focus on hematology. Blood. 2009;113(11):2394-2401.
91. Sun $\mathrm{H}$, et al. Increase in myeloid-derived suppressor cells (MDSCs) associated with minimal residual disease (MRD) detection in adult acute myeloid leukemia. Int J Hematol. 2015;102(5):579-586.

92. Wang L, et al. VISTA is highly expressed on MDSCs and mediates an inhibition of $\mathrm{T}$ cell response in patients with AML. Oncoimmunology. 2018;7(9):e1469594.

93. Lu T, Gabrilovich DI. Molecular pathways: tumor-infiltrating myeloid cells and reactive oxygen species in regulation of tumor microenvironment. Clin Cancer Res. 2012;18(18):4877-4882.

94. Kusmartsev S, Nefedova Y, Yoder D, Gabrilovich DI. Antigen-specific inhibition of CD8+ T cell response by immature myeloid cells in cancer is mediated by reactive oxygen species. J Immunol. 2004;172(2):989-999.

95. Pyzer AR, et al. MUC1-mediated induction of myeloid-derived suppressor cells in patients with acute myeloid leukemia. Blood. 2017;129(13):1791-1801.

96. Kittang AO, et al. Expansion of myeloid derived suppressor cells correlates with number of $\mathrm{T}$ regulatory cells and disease progression in myelodysplastic syndrome. Oncoimmunology. 2016;5(2):e1062208.

97. Mangaonkar A, et al. A novel immunohistochemical score to predict early mortality in acute myeloid leukemia patients based on indoleamine 2,3 dioxygenase expression. Sci Rep. 2017;7(1):12892.

98. Fukuno K, et al. Expression of indoleamine 2,3-dioxygenase in leukemic cells indicates an unfavorable prognosis in acute myeloid leukemia patients with intermediate-risk cytogenetics. Leuk Lymphoma. 2015;56(5):1398-1405.

99. Folgiero V, et al. Indoleamine 2,3-dioxygenase 1 (IDO1) activity in leukemia blasts correlates with poor outcome in childhood acute myeloid leukemia. Oncotarget. 2014;5(8):2052-2064.

100.Curti A, et al. Modulation of tryptophan catabolism by human leukemic cells results in the conversion of CD25- into CD25+ T regulatory cells. Blood.2007;109(7):2871-2877.

101.Mussai F, et al. Acute myeloid leukemia creates an arginase-dependent immunosuppressive microenvironment. Blood. 2013;122(5):749-758.

102. Deng M, et al. LILRB4 signalling in leukaemia cells mediates $\mathrm{T}$ cell suppression and tumour infiltration. Nature. 2018;562(7728):605-609.

103. Pinto A, Maio M, Attadia V, Zappacosta S, Cimino R. Modulation of HLA-DR antigens expression in human myeloid leukaemia cells by cytarabine and 5-aza-2'-deoxycytidine. Lancet. 1984;2(8407):867-868.

104.Kroemer G, Galluzzi L, Kepp O, Zitvogel L. Immunogenic cell death in cancer therapy. Annu Rev Immunol. 2013;31:51-72.

105. Fucikova J, et al. Calreticulin exposure by malignant blasts correlates with robust anticancer immunity and improved clinical outcome in AML patients. Blood. 2016;128(26):3113-3124.

106. Ocadlikova D, et al. Chemotherapy-induced tumor cell death at the crossroads between immunogenicity and immunotolerance: focus on acute myeloid leukemia. Front Oncol. 2019;9:1004.
107. Shih AH, Abdel-Wahab O, Patel JP, Levine RL. The role of mutations in epigenetic regulators in myeloid malignancies. Nat Rev Cancer. 2012;12(9):599-612.

108. Di Giacomo AM, et al. Guadecitabine plus ipilimumab in unresectable melanoma: the NIBIT-M4 clinical trial. Clin Cancer Res. 2019;25(24):7351-7362.

109. Goodyear O, et al. Induction of a CD8+ T-cell response to the MAGE cancer testis antigen by combined treatment with azacitidine and sodium valproate in patients with acute myeloid leukemia and myelodysplasia. Blood. 2010;116(11):1908-1918.

110. Chiappinelli KB, et al. Inhibiting DNA methylation causes an interferon response in cancer via dsRNA including endogenous retroviruses. Cell. 2017;169(2):361.

111. Roulois D, et al. DNA-demethylating agents target colorectal cancer cells by inducing viral mimicry by endogenous transcripts. Cell. 2015;162(5):961-973.

112. Fozza C, et al. Azacitidine improves the T-cell repertoire in patients with myelodysplastic syndromes and acute myeloid leukemia with multilineage dysplasia. Leuk Res. 2015;39(9):957-963.

113. Craddock $\mathrm{C}$, et al. Tolerability and clinical activity of post-transplantation azacitidine in patients allografted for acute myeloid leukemia treated on the RICAZA trial. Biol Blood Marrow Transplant. 2016;22(2):385-390.

114. Ishikawa T, et al. Graft-versus-leukemia effect with a WT1-specific T-cell response induced by azacitidine and donor lymphocyte infusions after allogeneic hematopoietic stem cell transplantation. Cytotherapy. 2017;19(4):514-520.

115. Guillaume T, et al. Prospective phase II study of prophylactic low-dose azacitidine and donor lymphocyte infusions following allogeneic hematopoietic stem cell transplantation for high-risk acute myeloid leukemia and myelodysplastic syndrome. Bone Marrow Transplant. 2019;54(11):1815-1826.

116. Yang H, et al. Expression of PD-L1, PD-L2, PD-1 and CTLA4 in myelodysplastic syndromes is enhanced by treatment with hypomethylating agents. Leukemia. 2014;28(6):1280-1288.

117. Goodyear OC, et al. Azacitidine augments expansion of regulatory $\mathrm{T}$ cells after allogeneic stem cel transplantation in patients with acute myeloid leukemia (AML). Blood. 2012;119(14):3361-3369.

118. Mathew NR, et al. Sorafenib promotes graft-versus-leukemia activity in mice and humans through IL-15 production in FLT3-ITD-mutant leukemia cells. Nat Med. 2018;24(3):282-291.

119. Hughes A, et al. CML patients with deep molecular responses to TKI have restored immune effectors and decreased PD-1 and immune suppressors. Blood. 2017;129(9):1166-1176.

120. Casey SC, et al. MYC regulates the antitumor immune response through CD47 and PD-L1. Science. 2016;352(6282):227-231.

121. Canon J, et al. The clinical KRAS(G12C) inhibitor AMG 510 drives anti-tumour immunity. Nature. 2019;575(7781):217-223.

122. Sekeres MA, et al. Randomized phase IIb study of low-dose cytarabine and lintuzumab versus lowdose cytarabine and placebo in older adults with 
untreated acute myeloid leukemia. Haematologica. 2013;98(1):119-128.

123. Raza A, et al. Complete remissions observed in acute myeloid leukemia following prolonged exposure to lintuzumab: a phase 1 trial. Leuk Lymphoma. 2009;50(8):1336-1344.

124. Morsink LM, Walter RB. Novel monoclonal antibody-based therapies for acute myeloid leukemia. Best Pract Res Clin Haematol. 2019;32(2):116-126.

125. Gutbrodt KL, et al. Antibody-based delivery of interleukin-2 to neovasculature has potent activity against acute myeloid leukemia. Sci Transl Med. 2013;5(201):201ra118.

126.Vasu S, et al. Decitabine enhances anti-CD33 monoclonal antibody BI 836858-mediated natural killer ADCC against AML blasts. Blood. 2016;127(23):2879-2889.

127. Hinterbrandner M, et al. Blocking CD70/CD27 signaling in combination with hypomethylating agents eradicates human CD34+ AML stem and progenitor cells in vitro and in vivo. Blood. 2017;130(suppl 1):2652.

128. Ochsenbein AF, et al. Argx-110 targeting CD70, in combination with azacitidine, shows favorable safety profile and promising anti-leukemia activity in newly diagnosed AML patients in an ongoing phase $1 / 2$ clinical trial. Blood. 2018;132(suppl 1):2680-2680.

129.Sallman DA, et al. The first-in-class anti-CD47 antibody magrolimab (5F9) in combination with azacitidine is effective in MDS and AML patients: ongoing phase $1 \mathrm{~b}$ results. Blood. 2019;134(suppl 1):569.

130. Castaigne $\mathrm{S}$, et al. Effect of gemtuzumab ozogamicin on survival of adult patients with de-novo acute myeloid leukaemia (ALFA-0701): a randomised, open-label, phase 3 study. Lancet. 2012;379(9825):1508-1516.

131. Burnett AK, et al. Addition of gemtuzumab ozogamicin to induction chemotherapy improves survival in older patients with acute myeloid leukemia. JClin Oncol. 2012;30(32):3924-3931.

132. Appelbaum FR, Bernstein ID. Gemtuzumab ozogamicin for acute myeloid leukemia. Blood. 2017;130(22):2373-2376

133. Burnett AK, et al. Identification of patients with acute myeloblastic leukemia who benefit from the addition of gemtuzumab ozogamicin: results of the MRC AML15 trial. J Clin Oncol. 2011;29(4):369-377.

134.Daver NG, et al. Clinical profile of IMGN632, a novel CD123-targeting antibody-drug conjugate (ADC), in patients with relapsed/refractory $(\mathrm{R} / \mathrm{R})$ acute myeloid leukemia (AML) or blastic plasmacytoid dendritic cell neoplasm (BPDCN). Blood. 2019;134(suppl 1):734.

135. Vadakekolathu J, et al. Immune gene expression profiling in children and adults with acute myeloid leukemia identifies distinct phenotypic patterns. Blood. 2017;130(suppl 1):3942.

136. Rutella S, et al. Adaptive immune gene signatures correlate with response to flotetuzumab, a CD123 $\times \mathrm{CD} 3$ bispecific DART ${ }^{\circledast}$ molecule, in patients with relapsed/refractory acute myeloid leukemia. Blood. 2018;132(suppl 1):444.

137. Uy GL, et al. Flotetuzumab, an investigational CD123 x CD3 bispecific DART ${ }^{\circledR}$ protein, in sal- vage therapy for primary refractory and early relapsed acute myeloid leukemia (AML) patients. Blood. 2019;134(suppl 1):733.

138. Uy GL et al. Phase 1 cohort expansion of flotetuzumab, a CD123 $\times \mathrm{CD} 3$ bispecific DART ${ }^{\circledast}$ protein in patients with relapsed/refractory acute myeloid leukemia (AML). Blood. 2018;132(suppl 1):764.

139. Herrmann $\mathrm{M}$, et al. Bifunctional PD $-1 \times \alpha \mathrm{CD} 3 \times$ $\alpha \mathrm{CD} 33$ fusion protein reverses adaptive immune escape in acute myeloid leukemia. Blood. 2018;132(23):2484-2494.

140.Kloss CC, Condomines M, Cartellieri M, Bachmann M, Sadelain M. Combinatorial antigen recognition with balanced signaling promotes selective tumor eradication by engineered $\mathrm{T}$ cells. Nat Biotechnol. 2013;31(1):71-75.

141. Tasian SK, et al. Optimized depletion of chimeric antigen receptor $\mathrm{T}$ cells in murine xenograft models of human acute myeloid leukemia. Blood. 2017;129(17):2395-2407.

142. Tang X, et al. First-in-man clinical trial of CAR NK-92 cells: safety test of CD33-CAR NK-92 cells in patients with relapsed and refractory acute myeloid leukemia. Am J Cancer Res. 2018;8(6):1083-1089.

143. Kim MY, et al. Genetic inactivation of CD33 in hematopoietic stem cells to enable CAR T cell immunotherapy for acute myeloid leukemia. Cell. 2018;173(6):1439-1453.e19.

144. Borot F, et al. Gene-edited stem cells enable CD33-directed immune therapy for myeloid malignancies. Proc Natl Acad Sci U S A. 2019;116(24):11978-11987.

145. Li S, et al. CD33-specific chimeric antigen receptor $\mathrm{T}$ cells with different co-stimulators showed potent anti-leukemia efficacy and different phenotype. Hum Gene Ther. 2018;29(5):626-639.

146.Dutour A, et al. In vitro and in vivo antitumor effect of anti-CD33 chimeric receptor-expressing EBV-CTL against CD33 acute myeloid leukemia. Adv Hematol. 2012;2012:683065.

147. Wang QS, et al. Treatment of CD33-directed chimeric antigen receptor-modified $\mathrm{T}$ cells in one patient with relapsed and refractory acute myeloid leukemia. Mol Ther. 2015;23(1):184-191.

148. Mardiros A, et al. T cells expressing CD123-specific chimeric antigen receptors exhibit specific cytolytic effector functions and antitumor effects against human acute myeloid leukemia. Blood. 2013;122(18):3138-3148.

149. Lynn RC, et al. Targeting of folate receptor $\beta$ on acute myeloid leukemia blasts with chimeric antigen receptor-expressing T cells. Blood. 2015;125(22):3466-3476.

150. Laborda E, et al. Development of a chimeric antigen receptor targeting C-type lectin-like molecule-1 for human acute myeloid leukemia. Int $J$ Mol Sci. 2017;18(11):E2259.

151. Jetani $\mathrm{H}$, et al. CAR T-cells targeting FLT3 have potent activity against $\mathrm{FLT}_{3} \mathrm{ITD}^{+} \mathrm{AML}$ and act synergistically with the FLT3-inhibitor crenolanib. Leukemia. 2018;32(5):1168-1179.

152. Peinert S, et al. Gene-modified T cells as immunotherapy for multiple myeloma and acute myeloid leukemia expressing the Lewis $\mathrm{Y}$ antigen. Gene Ther. 2010;17(5):678-686.

153. Zhang T, Barber A, Sentman CL. Generation of antitumor responses by genetic modification of primary human T cells with a chimeric NKG2D receptor. Cancer Res. 2006;66(11):5927-5933.

154. Leick $\mathrm{M}$ et al. Use of CD70 targeted chimeric antigen receptor (CAR) $\mathrm{T}$ cells for the treatment of acute myeloid leukemia (AML). Blood. 2019;134(suppl 1):4443.

155. Ritchie DS, et al. Persistence and efficacy of second generation CAR T cell against the LeY antigen in acute myeloid leukemia. Mol Ther. 2013;21(11):2122-2129.

156. Baumeister SH, et al. Phase I trial of autologous CAR T cells targeting NKG2D ligands in patients with AML/MDS and multiple myeloma. Cancer Immunol Res. 2019;7(1):100-112.

157. Sallman DA, et al. Results from the completed dose-escalation of the hematological arm of the phase I Think study evaluating multiple infusions of NKG2D-based CAR T-cells as standalone therapy in relapse/refractory acute myeloid leukemia and myelodysplastic syndrome patients. Blood. 2019;134(suppl 1):3826.

158. Al-Homsi AS, et al. Interim results from the phase I Deplethink trial evaluating the infusion of a NKG2D CAR T-cell therapy post a non-myeloablative conditioning in relapse or refractory acute myeloid leukemia and myelodysplastic syndrome patients. Blood. 2019;134(suppl 1):3844.

159. Provasi E, et al. Editing T cell specificity towards leukemia by zinc finger nucleases and lentiviral gene transfer. Nat Med. 2012;18(5):807-815.

160. Veomett N, et al. Therapeutic efficacy of an Fc-enhanced TCR-like antibody to the intracellular WT1 oncoprotein. Clin Cancer Res. 2014;20(15):4036-4046.

161. Chapuis AG, et al. Transferred WT1-reactive CD8+ T cells can mediate antileukemic activity and persist in post-transplant patients. Sci Transl Med. 2013;5(174):174ra27.

162.Tawara I, et al. Safety and persistence of WT1-specific T-cell receptor gene-transduced lymphocytes in patients with AML and MDS. Blood.2017;130(18):1985-1994.

163. Sandri S, et al. Effective control of acute myeloid leukaemia and acute lymphoblastic leukaemia progression by telomerase specific adoptive T-cell therapy. Oncotarget. 2017;8(50):86987-87001.

164. Spranger S, et al. TCR-transgenic lymphocytes specific for HMMR/Rhamm limit tumor outgrowth in vivo. Blood. 2012;119(15):3440-3449.

165. Di Stasi A, Jimenez AM, Minagawa K, Al-Obaidi M, Rezvani K. Review of the results of WT1 peptide vaccination strategies for myelodysplastic syndromes and acute myeloid leukemia from nine different studies. Front Immunol. 2015;6:36.

166. Maslak PG, et al. Phase 2 trial of a multivalent WT1 peptide vaccine (galinpepimut-S) in acute myeloid leukemia. Blood Adv. 2018;2(3):224-234.

167. Avigan D, Rosenblatt J. Vaccine therapy in hematologic malignancies. Blood. 2018;131(24):2640-2650.

168. van de Loosdrecht AA, et al. A novel allogeneic off-the-shelf dendritic cell vaccine for post-remission treatment of elderly patients with acute myeloid leukemia. Cancer Immunol Immunother. 2018;67(10):1505-1518.

169. Gong J, et al. Induction of anti-leukemic cytotoxic T lymphocytes by fusion of patient-derived den- 
dritic cells with autologous myeloblasts. Leuk Res. 2004;28(12):1303-1312.

170.Ott PA, et al. An immunogenic personal neoantigen vaccine for patients with melanoma. Nature. 2017;547(7662):217-221.

171. Keskin DB, et al. Neoantigen vaccine generates intratumoral $\mathrm{T}$ cell responses in phase Ib glioblastoma trial. Nature. 2019;565(7738):234-239.

172. Ferrari V, et al. A phase 1 clinical trial of personalized adoptive cellular therapy targeting myelodysplastic syndrome (MDS) stem cell neoantigens (PACTN). Blood. 2018;132(suppl 1):4373.

173. Bashey A, et al. CTLA4 blockade with ipilimum$a b$ to treat relapse of malignancy after allogeneic hematopoietic cell transplantation. Blood. 2009;113(7):1581.

174. Davids MS, et al. Ipilimumab for patients with relapse after allogeneic transplantation. $N$ Engl J Med. 2016;375(2):143-153.

175.Zeidan AM, et al. A multi-center phase I trial of ipilimumab in patients with myelodysplastic syndromes following hypomethylating agent failure. Clin Cancer Res. 2018;24(15):3519-3527.

176. Garcia JS, et al. Clinical and immunologic activity of ipilimumab following decitabine priming in post-allogeneic transplant and transplant-naïve patients with relapsed or refractory myelodysplastic syndromes and acute myeloid leukemia: a multi-center phase 1, two-arm, dose-escalation study. Blood. 2019;134(suppl 1):2015.

177. Daver NG, et al. Azacitidine (AZA) with nivolumab (Nivo), and AZA with Nivo + ipilimumab (Ipi) in relapsed/refractory acute myeloid leukemia: a non-randomized, prospective, phase 2 study. Blood. 2019;134(suppl 1):830.

178. Lindblad KE et al. Pembrolizumab and decitabine for refractory or relapsed acute myeloid leukemia. Blood. 2018;132(suppl 1):1437.

179. Gojo I, et al. Multi-center phase 2 study of pembroluzimab (Pembro) and azacitidine (AZA) in patients with relapsed/refractory acute myeloid leukemia (AML) and in newly diagnosed ( $\geq 65$ years) AML patients. Blood. 2019;134(suppl 1):832.

180. Daver N, et al. Phase IB/II study of nivolumab in combination with azacytidine (AZA) in patients (pts) with relapsed acute myeloid leukemia (AML). Blood. 2016;128(22):763.
181. Zeidan AM, et al. Efficacy and safety of azacitidine (AZA) in combination with the anti-PD-L1 durvalumab (durva) for the front-line treatment of older patients (pts) with acute myeloid leukemia (AML) who are unfit for intensive chemotherapy (IC) and patients with higher-risk myelodysplastic syndromes (HR-MDS): results from a large, international, randomized phase 2 study. Blood. 2019;134(suppl 1):829.

182. Herbrich S, et al. Single-cell mass cytometry identifies mechanisms of resistance to immunotherapy in AML. Blood. 2019;134(suppl 1):1428.

183. Ravandi F, et al. Idarubicin, cytarabine, and nivolumab in patients with newly diagnosed acute myeloid leukaemia or high-risk myelodysplastic syndrome: a single-arm, phase 2 study. Lancet Haematol. 2019;6(9):e480-e488.

184. Zeidner JF, et al. Genomics reveal potential biomarkers of response to pembrolizumab after high dose cytarabine in an ongoing phase II trial in relapsed/refractory AML. Blood. 2018;132(suppl 1):4054.

185.Zeidner JF, et al. Final clinical results of a phase II study of high dose cytarabine followed by pembrolizumab in relapsed/refractory AML. Blood. 2019;134(suppl 1):831.

186. Kadia TM, et al. Nivolumab (Nivo) maintenance (maint) in high-risk (HR) acute myeloid leukemia (AML) patients. J Clin Oncol. 2018;36(15 suppl):7014.

187. Liu $\mathrm{H}$ et al. TCR clonal evolution in AML patients in morphologic remission treated with anti-PD1 antibody, nivolumab. Blood. 2016;128(22):2325.

188. Davids MS, et al. A phase I/Ib study of nivolumab for relapsed hematologic malignancies after allogeneic hematopoietic cell transplantation (alloHCT). Blood. 2018;132(suppl 1):705.

189.Wong E, et al. Nivolumab for relapsed or residual haematological malignancies after allogeneic haematopoietic stem cell transplantation (NIVALLO). Blood. 2018;132(suppl 1):4633.

190. Kline J, et al. Pembrolizumab for the treatment of disease relapse following allogeneic hematopoietic cell transplantation. Blood. 2018;132(suppl 1):3415.

191. Schoch LK, et al. Immune checkpoint inhibitors as a bridge to allogeneic transplantation with posttransplant cyclophosphamide. Blood Adv.
2018;2(17):2226-2229.

192. Ravandi F, et al. A phase 1 first-in-human study of AMG 330, an anti-CD33 bispecific T-cell engager $\left(\right.$ BiTE $\left.^{\circledast}\right)$ antibody construct, in relapsed/refractory acute myeloid leukemia (R/R AML). Blood. 2018;132(suppl 1):25.

193. Krupka C, et al. CD33 target validation and sustained depletion of AML blasts in long-term cultures by the bispecific T-cell-engaging antibody AMG 330. Blood. 2014;123(3):356-365.

194. Aigner M, et al. T lymphocytes can be effectively recruited for ex vivo and in vivo lysis of AML blasts by a novel CD33/CD3-bispecific BiTE antibody construct. Leukemia. 2013;27(5):1107-1115.

195. Subklewe M, et al. Preliminary results from a phase 1 first-in-human study of AMG 673, a novel half-life extended (HLE) anti-CD33/CD3 $\mathrm{BiTE}^{\circledast}$ (bispecific T-cell engager) in patients with relapsed/refractory (R/R) acute myeloid leukemia (AML). Blood. 2019;134(suppl 1):833.

196. Westervelt P, et al. Phase 1 first-in-human trial of AMV564, a bivalent bispecific (2:2) CD33/ CD3 T-cell engager, in patients with relapsed/ refractory acute myeloid leukemia (AML). Blood. 2019;134(suppl 1):834.

197. Jacobs K, et al. Management of cytokine release syndrome in AML patients treated with flotetuzumab, a CD123 x CD3 bispecific DART ${ }^{\circledast}$ molecule for T-cell redirected therapy. Blood. 2018;132(suppl 1):2738.

198.Godwin J, et al. Bone marrow T cell changes by multiplex IHC after treatment with flotetuzumab, a CD123 x CD3 bispecific DART ${ }^{\circledast}$ protein, in a primary refractory t-AML patient. Blood. 2018;132(suppl 1):4065.

199. Ravandi F, et al. Complete responses in relapsed/refractory acute myeloid leukemia (AML) patients on a weekly dosing schedule of $\mathrm{XmAb}^{\varpi} 14045$, a CD123 $\mathrm{x}$ CD3 $\mathrm{T}$ cell-engaging bispecific antibody: initial results of a phase 1 study. Blood. 2018;132(suppl 1):763.

200.Borate U, et al. Phase Ib study of the anti-TIM-3 antibody MBG453 in combination with decitabine in patients with high-risk myelodysplastic syndrome (MDS) and acute myeloid leukemia (AML). Blood. 2019;134(suppl 1):570. 